\title{
Improved Vision from Severe Compressive Optic Neuropathy by Apical Cavernous Hemangioma
}

\author{
Hyera Kang ${ }^{a,}$ e Yasuhiro Takahashi ${ }^{a}$ Kunihiro Nishimura ${ }^{b}$ \\ Muneyoshi Yasuda ${ }^{c}$ Hiroyoshi Akutsu $^{d}$ Hirohiko Kakizaki ${ }^{a}$ \\ ${ }^{a}$ Department of Oculoplastic, Orbital and Lacrimal Surgery, Aichi Medical University \\ Hospital, and Departments of ${ }^{b}$ Otorhinolaryngology and ${ }^{c}$ Neurosurgery, Aichi Medical \\ University, Nagakute, and dDepartment of Neurosurgery, Faculty of Medicine, University \\ of Tsukuba, Tsukuba, Japan; ${ }^{e}$ Department of Ophthalmology, University of Seonam \\ College of Medicine, Presbyterian Medical Center, Jeonju-si, South Korea
}

\section{Key Words}

Cavernous hemangioma $\cdot$ Apical orbital tumor $\cdot$ Optic nerve $\cdot$ Vision loss $\cdot$ Critical flicker frequency

\begin{abstract}
A 59-year-old woman had a 1-year history of right vision loss. Her visual acuity was then 0.01 $\mathrm{OD}$, and the critical flicker frequency (CFF) was $8 \mathrm{~Hz} \mathrm{OD}$. Goldmann perimetry examination showed inferior suppression of the right visual field center. Funduscopic examination revealed normal coloring of the right optic disc. Imaging studies showed an apical oval tumor. The optic nerve was compressed by both the tumor and the superior rectus muscle/levator palpebrae superioris complex. The tumor was dissected from the surrounding tissues and completely extracted. Histopathologic examination confirmed a cavernous hemangioma. The patient underwent three cycles of postoperative steroid pulse therapy. One year after the surgery, her visual acuity and CFF improved to 1.0 and $32 \mathrm{~Hz} O D$, respectively. Her right visual field was within the normal range.

(C) 2016 The Author(s)

Published by S. Karger AG, Basel
\end{abstract}

\section{Introduction}

Apical cavernous hemangiomas may induce the development of compressive optic neuropathy [1]. Because such tumors slowly increase in size [1], the compressive optic neuropa-

\section{KARGER}

Hirohiko Kakizaki, MD, PhD

Department of Oculoplastic, Orbital and Lacrimal Surgery

Aichi Medical University Hospital

1-1 Yazakokarimata, Nagakute, Aichi 480-1195 (Japan)

E-Mail cosme@d1.dion.ne.jp 
Kang et al.: Improved Vision from Severe Compressive Optic Neuropathy by Apical Cavernous Hemangioma

thy insidiously progresses over a long period. Although mildly or moderately decreased vision commonly improves after removal of a tumor, severe vision impairment is frequently irreversible despite complete resection of the tumor [2].

We herein present a case involving a patient with severely decreased visual acuity due to compressive optic neuropathy caused by an apical cavernous hemangioma. The patient's visual acuity normalized after complete removal of the tumor.

\section{Case Report}

A 59-year-old woman presented with a 1-year history of decreased vision in the right eye. She had previously been treated for eosinophilic sinusitis and asthma. The first ophthalmic examination revealed a visual acuity of $0.01 \mathrm{OD}$ and $1.2 \mathrm{OS}$. She exhibited a right relative afferent pupillary defect. The critical flicker frequency (CFF), which decreases with optic nerve damage, was $8 \mathrm{~Hz}$ OD and $35 \mathrm{~Hz}$ OS (normal: >35 Hz). Goldmann perimetry showed inferior suppression of the right visual field center (fig. 1a), but no abnormalities on the left. The binocular single vision field could not be assessed because of the severely decreased vision in the right eye. Hertel exophthalmometry showed proptoses of $18.5 \mathrm{~mm}$ OD and $16.5 \mathrm{~mm}$ OS. A slit-lamp examination revealed no signs of ocular disease. A funduscopic examination showed normal coloring of the right optic disc (fig. 1b). Computed tomographic and magnetic resonance images (MRI) indicated an oval orbital mass located between the medial and inferior rectus muscles at the orbital apex (fig. 1c, d). The mass was isointense to gray matter on T1-weighted MRI and hyperintense to gray matter on T2-weighted MRI. Because the patient had asthma, we did not perform gadolinium-enhanced MRI. Although the optic nerve was compressed by both the tumor and the superior rectus muscle/levator palpebrae superioris complex, the inferior visual defect may be due to the compression by the muscle. Opacities were observed in the bilateral ethmoid, maxillary, and frontal sinuses.

We approached the tumor using an endoscopic bimanual binarial technique [3]. The intersinus septum of the sphenoid sinus was removed to connect the right and left sinuses. The tumor location was confirmed under navigation guidance, and the lamina papyracea was partly removed. The tumor was easily dissected from the surrounding tissues using a suction elevator and a suction curette, and completely removed along with its capsule. During the surgery, we cauterized bleeding points using a suction monopolar, which provided a clear surgical field. The histopathologic findings of the tumor were consistent with a cavernous hemangioma. As the patient's vision was severely impaired, we used steroids in expectation of its neuroprotection effect. The patient underwent three cycles of steroid pulse therapy postoperatively (one cycle: $10 \mathrm{mg} / \mathrm{kg}$ /day of intravenous methylprednisolone for 3 days) with reference to the therapeutic protocol for dysthyroid optic neuropathy [4]. After the first cycle of steroid pulse therapy, her visual acuity improved to $0.6 \mathrm{OD}$, although the CFF in the right eye did not show significant change $(11 \mathrm{~Hz}$ ) (fig. 1E). Upon completion of the steroid pulse therapy, her visual acuity and CFF in the right eye were 0.7 and $17 \mathrm{~Hz}$, respectively. Her visual acuity and CFF gradually improved thereafter, and at the 1-year follow-up, these values were 1.0 and $32 \mathrm{~Hz}$, respectively. She showed no relative afferent pupillary defect at that time. Goldmann perimetry revealed a normal visual field in the right eye. Although her binocular single vision field was limited to $30^{\circ}$ in the left gaze, she did not notice diplopia during her daily activities. 
Kang et al.: Improved Vision from Severe Compressive Optic Neuropathy by Apical Cavernous Hemangioma

\section{Discussion}

We have herein presented a case of compressive optic neuropathy with severely decreased visual acuity caused by an apical cavernous hemangioma. The visual acuity normalized after complete removal of the tumor. Although six cases of severe vision loss $(<20 / 200)$ caused by an apical cavernous hemangioma have been reported, the visual acuity returned to the normal range postoperatively in only 1 patient (table 1) [2, 5-8].

In the present case, the color of the optic disc was normal preoperatively (fig. 1b), and a partial central scotoma was present in the right eye (fig. 1). Previous studies have reported similar findings with good postoperative recovery of visual function after tumor extraction. One case involved a partially pale optic disc (table 1) [5], and three cases involved a partial central scotoma; however, visual acuity was not shown in these three cases [1]. These findings may indicate reversible visual function.

The cavernous hemangioma in our patient was easily dissected from the surrounding tissues and completely removed with its capsule. A cavernous hemangioma occasionally grows at the orbital apex in a pear shape [7], which implies firm adhesion of the capsule to the surrounding tissues $[1,7]$. Nerves and vessels are frequently damaged during dissection of the capsule in such cases, resulting in a poor postoperative visual course [7]. However, the shape of the tumor was oval in the present case, indicating less adhesion between the capsule and the surrounding tissues. This may have allowed for the easy dissection of the tumor and the subsequent good postoperative visual acuity.

In conclusion, we report a case involving compressive optic neuropathy with severely decreased visual acuity caused by an apical cavernous hemangioma. The patient's visual acuity normalized after complete removal of the hemangioma. The good postoperative visual acuity achieved in this case may have been associated with the normally colored optic disc, the partial central scotoma, and the easy dissection of the oval hemangioma.

\section{Statement of Ethics}

This study was approved by the Ethics Committee of Aichi Medical University (No. 2015-020) and adhered to the tenets of the 1964 Declaration of Helsinki. Written informed consent was obtained from the patient for publication of this case report and any accompanying images.

\section{Disclosure Statement}

The authors declare that they have no competing interests.

\section{References}

1 Harris GJ: Perspective: cavernous hemangioma of the orbital apex: pathogenic considerations in surgical management. Am J Ophthalmol 2010;150:764-773.

2 Wu W, Selva D, Jiang F, et al: Endoscopic transethmoidal approach with or without medial rectus detachment for orbital apical cavernous hemangiomas. Am J Ophthalmol 2013;156:593-599.

-3 Heady DY Jr, Lee NG, Freitag SK, Bleier BS: Endoscopic bimanual approach to an intraconal cavernous hemangioma of the orbital apex with vascularized flap reconstruction. Ophthal Plast Reconstr Surg 2014;30:e104-e106. 
Case Reports in

Ophthalmology

\begin{tabular}{l|l|}
\hline Case Rep Ophthalmol 2016;7:179-183 \\
\hline DOI: 10.1159/000445316 & $\begin{array}{l}\text { ○ } 2016 \text { The Author(s). Published by S. Karger AG, Basel } \\
\text { www.karger.com/cop }\end{array}$ \\
\hline
\end{tabular}

Kang et al.: Improved Vision from Severe Compressive Optic Neuropathy by Apical Cavernous Hemangioma

-4 Bartalena L, Baldeschi L, Dickinson A, Eckstein A, Kendall-Taylor P, Marcocci C, Mourits M, Perros P, Boboridis K, Boschi A, Currò N, Daumerie C, Kahaly GJ, Krassas GE, Lane CM, Lazarus JH, Marinò M, Nardi M, Neoh C, Orgiazzi J, Pearce S, Pinchera A, Pitz S, Salvi M, Sivelli P, Stahl M, von Arx G, Wiersinga WM: European Group on Graves' Orbitopathy (EUGOGO). Consensus statement of the European Group on Graves' Orbitopathy (EUGOGO) on management of GO. Eur J Endocrinol 2008;158:273-285.

-5 Yan J, Li, Y, Wu Z: Orbital cavernous hemangioma with bone erosion. Graefe's Arch Clin Exp Ophthalmol 2006;244:1534-1535.

6 Tsirbas A, Kazim M, Close L: Endoscopic approach to orbital apex lesions. Ophthal Plast Reconstr Surg 2005;21:271-275.

7 Kloos R, Mourits D, Saeed P, Mourits M: Orbital apex cavernous hemangioma - Beware of the pear! Acta Ophthalmol 2013;91:e328-e329.

8 Maus M, Goldman W: Removal of orbital apex hemangioma using new transorbital craniotomy through suprabrow approach. Ophthal Plast Reconstr Surg 1999;15:166-170.

Table 1. Cases of severe vision loss caused by an apical cavernous hemangioma

\begin{tabular}{|c|c|c|c|c|c|c|c|c|}
\hline \multirow[t]{2}{*}{ First author, year } & \multirow{2}{*}{\multicolumn{2}{|c|}{$\begin{array}{l}\text { Case No. (if Age, } \\
\text { case se- years } \\
\text { ries) }\end{array}$}} & \multirow[t]{2}{*}{ Sex } & \multirow[t]{2}{*}{ History } & \multirow[t]{2}{*}{ Optic disc color } & \multirow[t]{2}{*}{ Mass position } & \multicolumn{2}{|l|}{ BCVA } \\
\hline & & & & & & & $\begin{array}{l}\text { pre- } \\
\text { operative }\end{array}$ & $\begin{array}{l}\text { post- } \\
\text { operative }\end{array}$ \\
\hline Maus [8], 1999 & - & 35 & $\mathrm{~F}$ & 12 months & pale & superolateral & $\mathrm{CF}$ & $\mathrm{CF}$ \\
\hline Tsirbas [6], 2005 & 1 & 49 & $\mathrm{~F}$ & 2 years & pale & inferior & $20 / 400$ & $20 / 40$ \\
\hline Yan [5], 2006 & - & 43 & M & 13 years & moderately pale & whole retrobulbar space & $20 / 400$ & $20 / 15$ \\
\hline Kloos [7], 2013 & 3 & a & - & - & - & - & LP & $\mathrm{b}$ \\
\hline \multirow[t]{2}{*}{ Wu [2], 2013} & 2 & 35 & $\mathrm{~F}$ & 6 months & pale & optic canal & $\mathrm{CF}$ & $6 / 60$ \\
\hline & 10 & 45 & $\mathrm{~F}$ & 38 months & pale & medial & $\mathrm{CF}$ & $\mathrm{CF}$ \\
\hline Present case & - & 59 & $\mathrm{~F}$ & 1 year & normal & inferomedial & 0.01 & 1.0 \\
\hline
\end{tabular}

$\mathrm{BCVA}=$ Best-corrected visual acuity; $\mathrm{CF}=$ counting finger; $\mathrm{LP}=$ light perception .

a The age of case No. 3 was not shown; patients' ages ranged from 37 to 60 years. ${ }^{\mathrm{b}}$ The postoperative best-corrected visual acuity in case No. 3 was not shown, but was mentioned as having either no light perception or counting finger. 


\section{Case Reports in \\ Ophthalmology}

\begin{tabular}{l|l}
\hline Case Rep Ophthalmol 2016;7:179-183 \\
\hline DOI: 10.1159/000445316 & $\begin{array}{l}\text { ○ } 2016 \text { The Author(s). Published by S. Karger AG, Basel } \\
\text { www.karger.com/cop }\end{array}$ \\
\hline
\end{tabular}

Kang et al.: Improved Vision from Severe Compressive Optic Neuropathy by Apical Cavernous Hemangioma
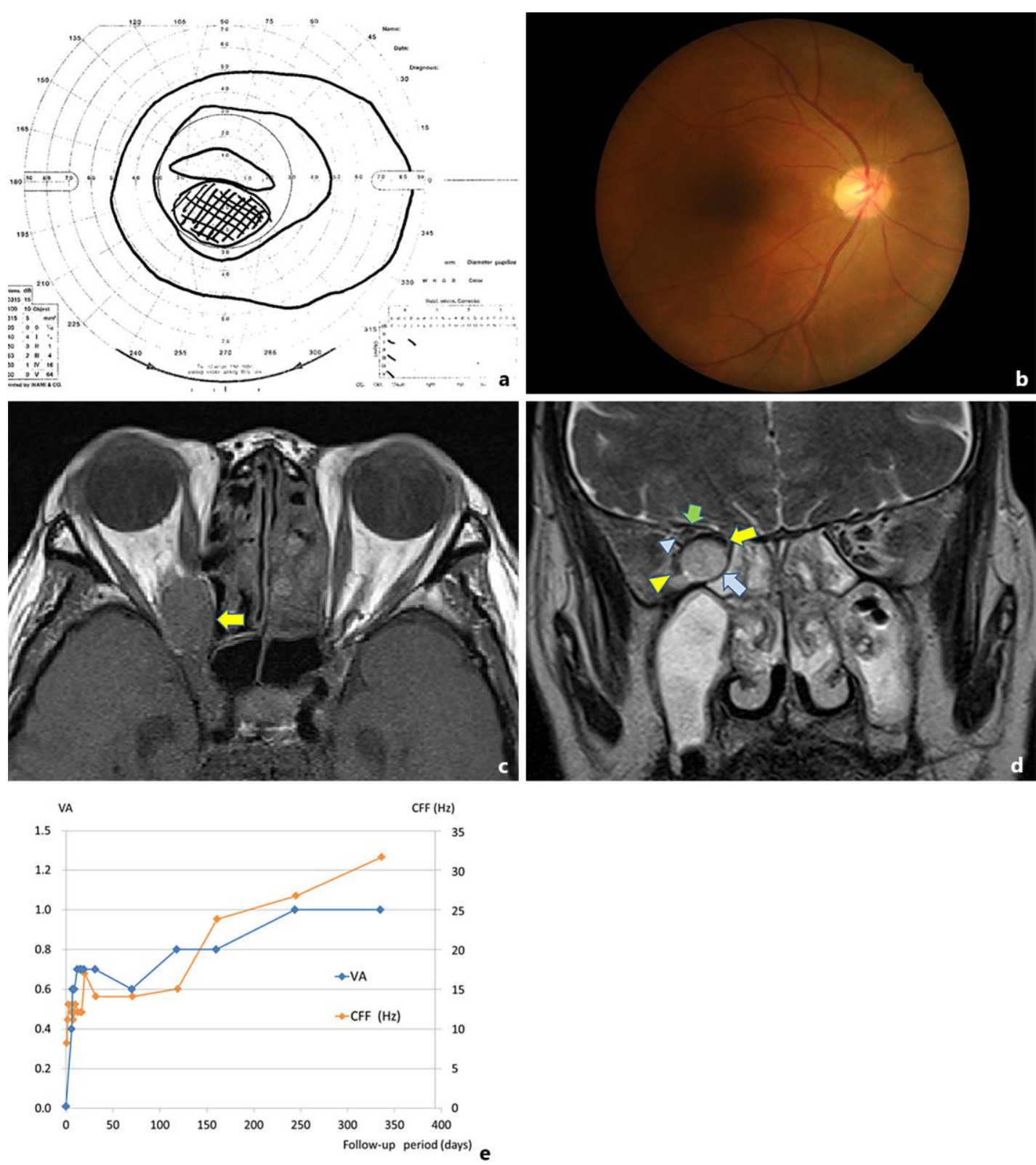

Fig. 1. a Goldmann perimetry showing inferior suppression of the visual field center in the right eye. b Right funduscopic examination showing normal coloring of the optic disc. c Axial T1-weighted MRI showing an oval tumor at the orbital apex (arrow). The mass was isointense to gray matter. $\mathbf{d}$ A coronal T2-weighted MRI showing a hyperintense tumor (blue arrow) to gray matter between the medial (yellow arrow) and inferior rectus muscles (yellow arrowhead). The optic nerve (blue arrowhead) is sandwiched by both the tumor and the superior rectus muscle/levator palpebrae superioris complex (green arrow). e Courses of best-corrected visual acuity and CFF. VA = Visual acuity. 